Journal of Healthcare Technology and Medicine Vol. 5 No. 2 Oktober 2019

Universitas Ubudiyah Indonesia

e-ISSN : 2615-109X

\title{
Analisis Faktor Faktor Yang Berhubungan Dengan Kelancaran ASI Pada Ibu Menyusui Di Wilayah Kerja Puskesmas Lhoong Kabupaten Aceh Besar
}

\section{Analysis Of Factors Associated with Smooth Breastfeeding in Breastfeeding Mothers in the Lhoong Community Health Center in Aceh Besar District}

\author{
Nuzulul Rahmi ${ }^{* 1}$, Merleni \\ ${ }^{1}$ Program Studi D-III Kebidanan Fakultas Ilmu Kesehatan Universitas Ubudiyah Indonesia, Jl. Alue Naga Desa \\ Tibang Kota Banda Aceh \\ ${ }^{2}$ Program Studi D-IV Kebidanan Fakultas Ilmu Kesehatan Universitas Ubudiyah Indonesia, Jl. Alue Naga Desa \\ Tibang Kota Banda Aceh \\ *Korespondesnsi Penulis: Nuzulul_r@uui.ac.id" ${ }^{* 1}$, marleni94@gmail.com²
}

\begin{abstract}
Abstrak
Air susu ibu (ASI) merupakan nutrisi alamiah terbaik bagi bayi karena mengandung kebutuhan energi dan zat yang dibutuhkan selama enam bulan pertama kehidupan bayi. Namun, ada kalanya seorang ibu mengalami masalah dalam pemberian ASI, kendala yang utama adalah karena produksi ASI tidak lancar (Saleha, 2013). Data yang diperoleh dari Puskesmas Lhoong Kabupaten Aceh Besar, pada tahun 2017 sasaran ASI eksklusif sebanyak 277 orang, dan yang memberikan ASI eksklusif hanya 135 orang (48,7\%). Sedangkan jumlah ibu menyusui (bayi usia 0-6 bulan) periode Januari-November 2018 sebanyak 161 orang, yang mengalami kelancaran ASI ada 92 orang $(57,1 \%)$, dan yang tidak lancar ASI ada 69 orang (42,8\%). Tujuan Penelitian ini untuk mengetahui faktor-faktor yang berhubungan dengan kelancaran ASI pada ibu menyusui di Wilayah Kerja Puskesmas Lhoong Kabupaten Aceh Besar. Penelitian ini bersifat analitik dengan pendekatan cross sectional. Populasi dalam penelitian ini adalah seluruh ibu seluruh ibu menyusui bayi usia 1-6 bulan yang berjumlah 150 orang. Tehnik pengambilan sampel dilakukan secara Simple Random Sampling dengan jumlah sampel yang didapatkan yaitu 60 orang. Pengumpulan data dilakukan pada tanggal 2-29 April 2019. Analisa data dilakukan dengan

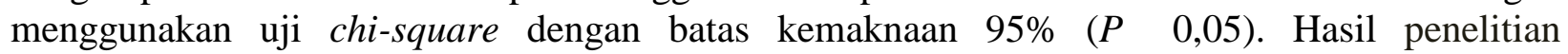
menunjukkan ada hubungan pengetahuan dengan kelancaran ASI pada ibu menyusui dimana $P$ value $=0,001$, ada hubungan IMD dengan kelancaran ASI pada ibu menyusui dimana $P$ value $=0,029$, ada hubungan frekuensi menyusui dengan kelancaran ASI pada ibu menyusui dimana $P$-value $=0,005$, dan ada hubungan perawatan payudara dengan kelancaran ASI pada ibu menyusui dimana $P$-value $=0,030$.
\end{abstract}

Kata Kunci : Kelancaran ASI, Pengetahuan, IMD, Frekuensi Menyusui, Perawatan Payudara 
Journal of Healthcare Technology and Medicine Vol. 5 No. 2 Oktober 2019

Universitas Ubudiyah Indonesia

e-ISSN : 2615-109X

\begin{abstract}
Breast milk (ASI) is the best natural nutrition for babies because it contains energy and substances needed during the first six months of a baby's life. However, there are times when a mother experiences problems in breastfeeding, the main obstacle is that milk production is not smooth (Saleha, 2013). Data obtained from the Lhoong Health Center in Aceh Besar District, in 2017 the target of exclusive breastfeeding was 277 people, and only 135 people gave exclusive breastfeeding (48.7\%). While the number of breastfeeding mothers (infants aged 0-6 months) in the January-November 2018 period was 161 people, 92 people (57.1\%) experienced fluency (57.1\%), and 69 people (42.8\%) were not fluent. The purpose of this study was to determine the factors associated with the smoothness of breastfeeding in breastfeeding mothers in the Work Area of Lhoong Health Center, Aceh Besar District. This research is analytic with cross sectional approach. The population in this study were all mothers of all breastfeeding infants aged 1-6 months, totaling 150 people. The sampling technique is done by simple random sampling with the number of samples obtained is 60 people. Data collection was carried out on 2-29 April 2019. Data analysis was performed using the chi-square test with a significance limit of 95\% (P $₫ .05)$. The results showed there was a relationship of knowledge with the smoothness of breastfeeding in breastfeeding mothers where P-value $=0.001$, there was an association of IMD with the smoothness of breastfeeding in breastfeeding mothers where P-value $=0.029$, there was a correlation between frequency of breastfeeding and smoothness of breastfeeding in breastfeeding mothers where $P$-value $=0.005$, and there is a relationship between breast care and the smoothness of breast milk in nursing mothers where P-value $=0.030$.
\end{abstract}

Keywords: Smooth ASI, Knowledge, IMD, Frequency of Breastfeeding, Breast Care

\title{
PENDAHULUAN
}

Pemberian ASI mempunyai pengaruh besar dalam perkembangan emosional yang dapat mempengaruhi hubungan batin antara ibu dan bayi (Lowdermilk, et.al, 2013). Air susu ibu (ASI) merupakan nutrisi alamiah terbaik bagi bayi karena mengandung kebutuhan energi dan zat yang dibutuhkan selama enam bulan pertama kehidupan bayi. Namun, ada kalanya seorang ibu mengalami masalah dalam pemberian ASI, kendala yang utama adalah karena produksi ASI tidak lancar (Saleha, 2013). Produksi ASI antara lain dapat dipengaruhi oleh makanan, ketenangan jiwa dan pikiran, penggunaan alat kontrasepsi, prawatan payudara, anatomi payudara, faktor fisiologi, pola istirahat, faktor isapan atau frekuensi menyusui, berat lahir bayi, umur kehamilan saat melahirkan dan konsumsi rokok dan alkohol (Dewi dan Sunarsih, 2013).

Banyak hal yang mempengaruhi kelancaran ASI, diantaranya ialah kurangnya pengetahuan ibu, hal ini menyebabkan ibu tidak mengerti tentang cara menyusui bayi yang tepat, manfaat ASI dan hambatan-hambatan yang mungkin terjadi pada proses menyusui seperti puting susu lecet, payudara bengkak, tersumbatnya saluran laktiferus atau duktus laktiferus (lactiverous duct), 
Journal of Healthcare Technology and Medicine Vol. 5 No. 2 Oktober 2019

Universitas Ubudiyah Indonesia

e-ISSN : 2615-109X

mastitis atau radang payudara, abses payudara, ASI kurang, bayi bingung puting susu, bayi enggan menyusu, bayi sering menangis, Bayi Berat Lahir Rendah (BBLR), bayi kembar, bayi sumbing, icterus pada neonatus, dan hal tersebut seringkali membuat sejumlah ibu putus asa (Ambarwati, 2013).

Data yang diperoleh dari Puskesmas Lhoong Kabupaten Aceh Besar, pada tahun 2017 sasaran ASI eksklusif sebanyak 277 orang, dan yang memberikan ASI eksklusif hanya 135 orang (48,7\%). Sedangkan jumlah ibu menyusui (bayi usia 0-6 bulan) periode Januari-November 2018 sebanyak 161 orang, yang mengalami kelancaran ASI ada 92 orang $(57,1 \%)$, dan yang tidak lancar ASI ada 69 orang (42,8\%). Hasil wawancara dengan 5 orang ibu menyusui, diperoleh bahwa 3 orang $(60 \%)$ ibu mengatakan bahwa saat bayi lahir tidak dilakukan tindakan IMD, pernah mengalami puting lecet sehingga tidak meningkatkan frekuensi menyusui dan isapan bayi khususnya pada saat istirahat. Selain itu ASI tidak keluar sehingga ibu memberikan susu formula karena merasa bayinya tidak cukup ASI, dan ibu tidak mengetahui bagaimana cara melakukan perawatan payudara yang benar. Sedangkan 2 orang (40\%) mengatakan bayinya menyusui dengan baik dan tidak memiliki masalah dalam pemberian ASI, ibu juga sering memberikan ASI pada bayi tanpa dijadwalkan pemberiannya.

\section{METODE PENELITIAN}

Penelitian ini bersifat analitik dengan pendekatan cross sectional. Populasi dalam penelitian ini adalah seluruh ibu menyusui bayi usia 1-6 bulan yang berjumlah 150 orang. Tehnik pengambilan sampel dilakukan secara Simple Random Sampling dengan jumlah sampel yang didapatkan yaitu 60 orang. Pengumpulan data dilakukan pada tanggal 2-29 April 2019. Analisa data dilakukan dengan menggunakan uji chi-square dengan batas kemaknaan $95 \%(P \leq 0,05)$. 
Journal of Healthcare Technology and Medicine Vol. 5 No. 2 Oktober 2019

Universitas Ubudiyah Indonesia

e-ISSN : 2615-109X

\section{HASIL DAN PEMBAHASAN}

Tabel 1.1 Distribusi Frekuensi Faktor-faktor yang Berhubungan dengan Kelancaran ASI Pada Ibu Menyusui di Wilayah Kerja Puskesmas Lhoong Kabupaten Aceh Besar Tahun 2019

\begin{tabular}{lcc}
\hline Variabel & Frekuensi & $\%$ \\
\hline Kelancaran ASI & 26 & 43,3 \\
1. Lancar & 34 & 56,7 \\
2. Tidak lancar & & \\
\hline Pengetahuan & 33 & 55 \\
1. Baik & 27 & 45 \\
2. Cukup & & \\
\hline IMD & 38 & 63,3 \\
1. Ada & 22 & 36,7 \\
2. Tidak & & \\
\hline Frekuensi Menyusui & 28 & 46,7 \\
1. Sering & 32 & 53,3 \\
2. Tidak sering & & \\
\hline Perawatan Payudara & 17 & 28,3 \\
1. Benar & 34 & 156,7 \\
2. Tidak benar & 9 & 100 \\
3. Tidak dilakukan & 60 & \\
\hline Total & & \\
\hline
\end{tabular}

Berdasarkan tabel 1.1 dapat dilihat bahwa sebagian besar kelancaran ASI berada pada kategori tidak lancar yaitu 34 responden (56,7\%), pengetahuan ibu berada pada kategori baik yaitu 33 responden (55\%), IMD berada pada kategori ada yaitu 38 responden $(63,3 \%)$, frekuensi menyusui berada pada kategori sering yaitu 28 responden $(46,7 \%)$, dan perawatan payudara berada pada kategori tidak benar yaitu 34 responden $(56,7 \%)$. 
Journal of Healthcare Technology and Medicine Vol. 5 No. 2 Oktober 2019

Universitas Ubudiyah Indonesia

e-ISSN : 2615-109X

Tabel 1.2 Analisis Faktor-Faktor Yang Berhubungan Dengan Kelancaran ASI Pada Ibu Menyusui di Wilayah Kerja Puskesmas Lhoong Kabupaten Aceh Besar Tahun 2019

\begin{tabular}{|c|c|c|c|c|c|c|c|c|}
\hline \multirow{3}{*}{ No } & \multirow{3}{*}{$\begin{array}{c}\text { Variabel } \\
\text { Independen }\end{array}$} & \multirow{3}{*}{ Katagori } & \multicolumn{4}{|c|}{ Kelancaran ASI } & \multirow{3}{*}{ Total } & \multirow{3}{*}{$\begin{array}{c}P \\
\text { Valu } \\
\boldsymbol{e}\end{array}$} \\
\hline & & & \multicolumn{2}{|c|}{ Lancar } & \multicolumn{2}{|c|}{ Tidak } & & \\
\hline & & & $\mathbf{n}$ & $\%$ & $\mathbf{n}$ & $\%$ & & \\
\hline \multirow{2}{*}{1.} & \multirow{2}{*}{ Pengetahuan } & Baik & 21 & 63,3 & 12 & 36,4 & 33 & \multirow{2}{*}{0,001} \\
\hline & & Cukup & 5 & 18,5 & 22 & 81,5 & 27 & \\
\hline \multirow{2}{*}{2.} & \multirow{2}{*}{ IMD } & Ada & 21 & 55,3 & 17 & 44,7 & 38 & \multirow{2}{*}{0,029} \\
\hline & & Tidak Ada & 5 & 22,7 & 17 & 77,3 & 22 & \\
\hline \multirow{2}{*}{3.} & \multirow{2}{*}{$\begin{array}{l}\text { Frukensi } \\
\text { Menyusui }\end{array}$} & Sering & 18 & 64,3 & 10 & 35,7 & 28 & \multirow{2}{*}{0,005} \\
\hline & & Tidak Sering & 8 & 25 & 24 & 75 & 32 & \\
\hline \multirow{3}{*}{4.} & \multirow{3}{*}{$\begin{array}{l}\text { Sosial } \\
\text { budaya }\end{array}$} & Benar & 11 & 64,7 & 6 & 35,3 & 17 & \multirow{3}{*}{0,030} \\
\hline & & Tidak Benar & 14 & 41,2 & 20 & 58,8 & 34 & \\
\hline & & $\begin{array}{l}\text { Tidak } \\
\text { Dilakukan }\end{array}$ & 1 & 11,1 & 8 & 88,9 & 9 & \\
\hline
\end{tabular}

Berdasarkan Tabel 1.2 di atas maka dapat dilihat hasil penelitian dan pembahasan sebagai berikut :

1. Hubungan Pengetahuan dengan kelancaran ASI pada Ibu Menyusui di Wilayah Kerja Puskesmas Lhoong Kabupaten Aceh Besar

Hasil penelitian menunjukkan bahwa dari 33 responden yang berpengetahuan baik ada $36,4 \%$ yang tidak ASI, sedangkan dari 27 responden yang berpengetahuan cukup ada 81,5\% yang tidak lancar ASI. Hasil analisa statistik dengan chi square test menunjukkan $P$-value= 0,001, artinya ada hubungan pengetahuan dengan kelancaran ASI pada ibu menyusui di Wilayah Kerja Puskesmas Lhoong Kabupaten Aceh Besar.

Hasil penelitian ini sesuai dengan penelitian yang dilakukan oleh Syamsinar (2015), hasil penelitian menunjukkan bahwa pengetahuan memiliki hubungan dengan kelancaran pengeluaran ASI pada ibu post partum di Ruang Nifas Rumah Sakit TK.II Pelamonia Makasar dengan P-value =0,002. Menurut asumsi penelitian Syamsina, pengetahuan ibu yang baik 
Journal of Healthcare Technology and Medicine Vol. 5 No. 2 Oktober 2019

Universitas Ubudiyah Indonesia

e-ISSN : 2615-109X

maka akan mempengaruhi kelancaran ASI ibu, karena ibu mengetahui bagaimana cara agar ASI ibu melimpah dan juga lancar.

Pengetahuan atau kognitif merupakan domain yang sangat penting untuk terbentuknya tindakan seseorang. Pengetahuan ada 2 macam yaitu pengetahuan umum dan pengetahuan khusus, dimana keduanya menjadi milik manusia berdasarkan pengalaman, baik pengalaman sendiri atau orang lain, yang amat penting adalah pengalaman ini harus sesuai dengan aspek objek yang diketahui, persesuaian pengetahuan objek adalah pengetahuan objektif dalam pengetahuan benar (Notoatmodjo, 2014). Manfaat pemberian ASI perlu diketahui oleh seorang ibu/orangtua bayi. Penyuluhan kurang dilaksanakan oleh masyarakat, salah satu faktornya adalah karena kurangnya petugas sehingga masyarakat kurang mendapat penerangan dan dorongan tentang manfaat ASI. Terlebih lagi jika ibu mempunyai pengalaman menyusui sebelumnya yang penuh dengan banyak kesulitan, lebih memungkinkan ibu untuk memilih tidak memberikan ASI (Safitri, 2016).

Menurut peneliti dalam penelitian ini, pengetahuan seseorang berhubungan erat dengan perilaku individu tersebut terhadap kelancaran ASI. Dari hasil penelitian dapat dilihat bahwa sebagian besar responden saat menyusui hanya memasukkan puting susu saja ke dalam mulut, padahal cara menyusui yang benar yaitu dengan memasukkan semua puting dan areola payudara sehingga ASI keluar dengan lancar. Selain itu, ibu menyusui bayinya juga tidak teratur pemberiannya. Ibu ynang sudah memiliki pengetahuan baik, maka akan mengetahui bahwa untuk kelancaran ASI diperlukan mengkonsumsi makanan yang sehat dan bergizi, banyak mengomsumsi air putih agar ibu menyusui tidak mengalami dehidrasi sehingga suplai ASI dapat berjalan dengan lancar dan ibu menyusui harus menjaga kondisi psikologisnya serta banyak istirahat agar kondisi tetap terjaga dengan baik.

\section{Hubungan IMD dengan Kelancaran ASI Pada Ibu Menyusui di Wilayah Kerja Puskesmas Lhoong Kabupaten Aceh Besar}

Hasil penelitian menunjukkan bahwa dari 38 responden yang ada dilakukan IMD ada 44,7\% yang tidak lancar ASI, sedangkan dari 22 responden yang tidak dilakukan IMD ada 77,3\% yang tidak lancar ASI. Hasil analisa statistik dengan chi square test menunjukkan $P$ value $=0,029$, artinya ada hubungan IMD dengan kelancaran ASI pada ibu menyusui di Wilayah Kerja Puskesmas Lhoong Kabupaten Aceh Besar. 
Journal of Healthcare Technology and Medicine Vol. 5 No. 2 Oktober 2019

Universitas Ubudiyah Indonesia

e-ISSN : 2615-109X

Hasil penelitian ini sejalan dengan penelitian yang dilakukan oleh Marlina (2014) hasil penelitiannya menunjukkan bahwa ada hubungan IMD dengan kelancaran pengeluaran ASI (p =0,000). Menurut asumsi penelitian Marlina, ibu yang melakukan Inisiasi Menyusu Dini (IMD) maka kontak emosi antara ibu dan bayi lebih dini dan lebih rapat, bayi dan ibu tidak stres, pernapasan dan detak jantung lebih stabil, dikarenakan oleh kontak kulit antara ibu dan bayi. Bayi yang diberi kesempatan menyusu dini lebih berhasil menyusui eksklusif dan akan menyusui lebih sering, antara 10-12 kali menyusui tiap 24 jam atau bahkan 18 kali sehingga pengeluaran ASI juga akan semakin lancar.

Hasil penelitian berbeda dengan penelitian yang dilakukan oleh Agusvina (2015), menunjukkan bahwa tidak ada hubungan IMD terhadap kelancaran ASI $(\mathrm{P}=0,122)$ dengan $\alpha=0,05$. Menurut asumsi penelitian Agusvina, ibu yang mengalami ketidaklancaran ASI karena tindakan IMD yang dilakukan saat persalinan belum sempurna sehingga bayi kurang menghisap dan mempengaruhi kelancaran ASI pada ibu.

Pada umumnya bayi baru lahir normal mempunyai kemampuan menghisap yang tinggi tetapi beberapa jam kemudian kemampuan menghisap menurun, maka sebaiknya bayi disusui segera setelah lahir. IMD yang diterapkan akan menyebabkan kulit bayi menempel pada perut ibu (skin to skin) sehingga mempertahankan suhu tubuh bayi tetap hangat. Ibu yang ingin melakukan inisiasi menyusu dini tentunya mendapatkan rangsangan hisapan aktif dan psikologi lebih cepat untuk mengeluarkan hormon-hormon laktasi (oksitosin dan prolaktin). Pelaksanaan IMD memanfaatkan keadaan bayi dalam keadaan terjaga (periode reaktivitas pertama) dan merangsang produksi oksitosin yang membantu pengeluaran plasenta dan menghindari peradarahan post partum, yang mendapat program IMD dapat secara dini belajar untuk memberikan rangsangan pada puting payudara sehingga meningkatkan peluang suksesnya proses menyusu sejak dini (Lisnawati, 2017).

Menurut peneliti dalam penelitian ini, responden yang mengalami pengeluaran ASI tidak lancar dikarenakan beberapa responden tersebut tidak tepat dalam penatalaksanaan IMD nya sehingga berpengaruh pada refleks hisap bayi yang merangsang pengeluaran ASI. Responden yang dilakukan inisisasi menyusu dini akan mendapatkan rangsangan pada puting ibu oleh hisapan bayi. Semakin cepat ada rangsangan hisapan dari puting ibu, maka proses pengeluaran ASI akan cepat. Karena dalam pelaksanaan IMD terjadi hentakan kepala bayi ke 
Journal of Healthcare Technology and Medicine Vol. 5 No. 2 Oktober 2019

Universitas Ubudiyah Indonesia

e-ISSN : 2615-109X

dada ibu, sentuhan tangan bayi ke puting susu, emutan dan jilatan bayi pada puting susu ibu merangsang pengeluaran hormon oksitosin yang dapat membuat ASI menjadi lancar.

\section{Hubungan Frukuensi Menyusui dengan Kelancaran ASI Pada Ibu Menyusui di Wilayah}

\section{Kerja Puskesmas Lhoong Kabupaten Aceh Besar}

Hasil penelitian menunjukkan bahwa dari 28 responden yang frekuensi menyusui sering ada 64,3\% yang tidak lancar ASI, sedangkan dari 32 responden yang frekuensi menyusui tidak sering ada 75,0\% yang ASI tidak lancar. Hasil analisa statistik dengan chi square test menunjukkan $P$-value $=0,005$, artinya ada hubungan frekuensi menyusui dengan kelancaran ASI pada ibu menyusui di Wilayah Kerja Puskesmas Lhoong Kabupaten Aceh Besar.

Hasil penelitian ini sesuai dengan penelitian yang dilakukan oleh Marlina (2014), hasil penelitian menunjukkan ada hubungan frekuensi menyusui dengan kelancaran pengeluaran ASI $(\mathrm{p}=0,001)$. Menurut asumsi penelitian Marlina, makin sering ibu menyusui dengan kedua payudara maka akan meningkatkan produksi ASI. Selama beberapa minggu pertama lebih baik menyusui melalui satu payudara saja dan jika sudah membiasakan diri, maka kedua puting akan lebih kuat menambah isapan sang bayi yang semakin lancar pengeluaran ASI.

Penelitian yang dilakukan oleh Sulistiyah, (2015), hasil uji statistik korelasi spearmenrank menunjukan, dimana nilai hitung lebih kecil dari $\alpha=0,01$, yang artinya terdapat hubungan antara frekuensi ibu menyusui pada bayi usia 0-6 bulan dengan kelancaran ASI. Menurut asumsi penelitian Sulistiyah, di dalam pemberian ASI (frekuensi ibu menyusui) sendiri sangat tergantung pada keuletan dan kemauan ibu untuk memberikan ASI. Selain itu faktor lain yang dapat meningkatkan adanya frekuensi menyusui yaitu adanya waktu luang ibu di rumah sehari-hari.

Kriteria kelancaran ASI sendiri dilihat dari ciri-ciri bayi yang cukup ASI antara lain bayi akan terlihat puas setelah menyusu, bayi akan tertidur pulas dan tidak menangis, bayi tampak sehat dan terdapat kenaikan berat badan rata-rata 500 gram setiap bulannya. Frekuensi bayi menyusu idealnya adalah $8-12$ x dalam 24 jam dan 10 sampai 20 menit untuk masingmasing payudara, dengan jarak menyusui dengan menyusui berikutnya yaitu antara satu setengah sampai 2 jam sekali. Tetapi sering ada yang lama, mungkin sampai setengah jam. Kondisi seperti ini tergantung pada kekuatan bayi menghisap, kecepatan menelan serta 
Journal of Healthcare Technology and Medicine Vol. 5 No. 2 Oktober 2019

Universitas Ubudiyah Indonesia

e-ISSN : 2615-109X

kenyamanan bayi saat disusui. Saat kenyang bayi akan melepaskan puting ibu (Angriany, 2017).

Menurut peneliti dalam penelitian ini, makin sering ibu menyusui dengan kedua payudara maka akan meningkatkan produksi ASI. Selama beberapa minggu pertama lebih baik menyusui melalui satu payudara saja dan jika sudah membiasakan diri, maka kedua puting akan lebih kuat menambah sedotan sang bayi yang makan meningkat, semakin sering ibu menyusui dapat merangsang otot polos susunan saraf disekitarnya dan meneruskan rangsangan ke otak untuk memproduksi ASI sehingga semakin banyak dilkukan isapan semakin lancar pengeluaran ASI dan kecukupan ASI pada bayi dapat tercukupi.

\section{Hubungan Perawatan Payudara dengan Kelancaran ASI Pada Ibu Menyusui di}

\section{Wilayah Kerja Puskesmas Lhoong Kabupaten Aceh Besar}

Hasil penelitian menunjukkan bahwa dari 17 responden yang benar perawatan payudara ada 35,3\% yang tidak lancar ASI, dari 34 responden yang tidak benar perawatan payudara ada 58,8\% yang tidak lancar ASI, sedangkan dari 9 responden yang tidak dilakukan perawatan payudara ada $88,9 \%$ yang tidak lancar ASI. Hasil analisa statistik dengan chi square test menunjukkan $P$-value $=0,030$, artinya ada hubungan perawatan payudara dengan kelancaran ASI pada ibu menyusui di Wilayah Kerja Puskesmas Lhoong Kabupaten Aceh Besar.

Hasil penelitian ini sesuai dengan penelitian yang dilakukan oleh Safitri (2016), hasil penelitian menunjukkan bahwa ada hubungan perawatan payudara dengan kelancaran produksi ASI (P-value=0,02). Menurut asumsi penelitian safitri, perawatan payudara yang dilakukan dengan benar dan teratur akan memudahkan bayi mengkonsumsi ASI. Pemeliharaan ini juga bisa merangsang keluarnya ASI dan mengurangi resiko luka saat menyusui.

Penelitian yang dilakukan oleh Solichah (2016) juga menunjukkan ada hubungan antara perawatan payudara pada ibu post partum dengan kelancaran pengeluaran ASI dengan $\mathrm{p}=$ 0,007. Menurut asumsi penelitian Solichah, demi keberhasilan menyusui, payudara memerlukan perawatan secara teratur. Perawatan payudara bertujuan agar selama masa menyusui produksi ASI cukup, tidak terjadi kelainan pada payudara dan agar bentuk payudara tetap baik selama menyusui. Perawatan payudara dapat dilakukan dengan rutin membersihkan payudara dan melakukan pijat payudara

Secara fisiologis sejak hari ketiga sampai hari keenam setelah persalinan, ketika ASI secara normal dihasilkan, payudara menjadi sangat penuh. Hal ini bersifat fisiologis 
Journal of Healthcare Technology and Medicine Vol. 5 No. 2 Oktober 2019

Universitas Ubudiyah Indonesia

e-ISSN : 2615-109X

dan dengan penghisapan yang efektif dan pengeluaran ASI oleh bayi, rasa penuh tersebut pulih dengan cepat. Namun dapat berkembang menjadi bendungan. Payudara terisi sangat penuh dengan ASI dan cairan jaringan. Aliran vena limpatik tersumbat, aliran susu menjadi terhambat dan tekanan pada saluran ASI dengan alveoli meningkat dengan merangsang kelenjar-kelenjar air susu melalui pemijatan. Pemijatan dilakukan dengan tujuan memberikan rangsangan pada kelenjar air susu ibu agar dapat memproduksi ASI, pengurutan dilakukan pada pagi dan sore hari, sebaiknya sebelum mandi. Gerakan pada perawatan payudara bermanfaat melancarkan reflek pengeluaran ASI. Selain itu juga merupakan cara efektif meningkatkan volume ASI (Solichah, 2016).

Menurut peneliti, perawatan payudara sangat berhubungan dengan kelancaran ASI. Demi keberhasilan menyusui, payudara memerlukan perawatan secara teratur. Perawatan payudara bertujuan agar selama masa menyusui produksi ASI cukup, tidak terjadi kelainan pada payudara dan agar bentuk payudara tetap baik selama menyusui. Ibu yang melakukan perawatan payudara rutin dan benar maka saluran aliran air susu dapat terbuka. Hasil penelitian menunjukkan responden yang tidak melakukan perawatan payudara mengalami ASI yang tidak lancar, dan hanya sedikit responden yang melakukan perawatan payudara dengan benar. Edukasi pendidikan tentang perawatan payudara perlu dilakukan pada ibu-ibu menyusui.

\section{KESEIMPULAN}

Setelah dilakukan uji statistik maka didapatkan kesimpulan ada hubungan pengetahuan dengan kelancaran ASI pada ibu menyusui dimana $P$-value $=0,001$, ada hubungan IMD dengan kelancaran ASI pada ibu menyusui dimana $P$-value $=0,029$, ada hubungan frekuensi menyusui dengan kelancaran ASI pada ibu menyusui dimana $P$-value $=0,005$, dan ada hubungan perawatan payudara dengan kelancaran ASI pada ibu menyusui dimana $P$-value $=0,030$.

\section{SARAN}

Diharapkan kepada tenaga kesehatan untuk dapat menyelenggarakan kegiatan penyuluhan dengan materi tentang kelancaran ASI dan juga penyebab ASI tidak lancar target program ASI ekslusif dan menyusui balita hingga usia 2 tahun dapat tercapai sehingga dapat menurunkan angka kesakitan dan kematian pada bayi. 
Journal of Healthcare Technology and Medicine Vol. 5 No. 2 Oktober 2019

Universitas Ubudiyah Indonesia

e-ISSN : 2615-109X

\section{DAFTAR PUSTAKA}

Agusvina, R, 2015. Hubungan Inisiasi Menyusu Dini Dengan Kelancaran ASI di Posyandu Kelurahan Cempaka Putih Ciputat Timur. Jurnal: Universitas Islam Negeri Syarif Hidayatullah Jakarta Edisi 2 Volume 4.

Ambarwati, E, dan Wulandari, D. 2014. Asuhan Kebidanan Nifas. Nuha Medika, Jogyakarta.

Angriany, R, 2017. Hubungan Frekuensi Menyusui Dengan Kelancaran Produksi Asi Ibu Post Partum Di Wilayah Kerja Puskesmas Peusangan Selatan Kabupaten Bireuen Provinsi Aceh. Jurnal Muara Sains, Teknologi, Kedokteran, dan Ilmu Kesehatan Edisi 1 Volume 2.

Dewi, V,N dan Sunarsih. 2013. Asuhan Kebidanan pada Ibu Nifas, Salemba Medika, Jakarta.

Marlina, 2014. Faktor-faktor yang Mempengaruhi Kelancaran Pengeluaran ASI Pada Ibu Menyusui Desa Mongal Kecamatan Bebesen Kabupaten Aceh Tengah. Jurnal: Program Studi D-IV Kebidanan Fakultas Ilmu Masyarakat Universitas Ubudiyah Indonesia.

Notoatmodjo., S, 2014. Kesehatan Masyarakat Ilmu dan Seni. Rineka Cipta, Jakarta.

Saleha, S, 2013. Asuhan Kebidanan Pada Masa Nifas. Salemba Medika, Jakarta.

Safitri, I, 2016. Faktor-faktor yang Mempengaruhi Kelancaran Produksi ASI Pada Ibu Menyusui di Desa Bendan Kecamatan Banyudono Kabupaten Boyolali. Jurnal: Fakultas Ilmu Kesehatan Universitas Muhammadiyah Surakarta.

Sulistyah, 2016. Hubungan Antara Frekuensi Ibu Menyusui Pada Bayi 0-6 Bulan Dengan Kelancaran ASI (Studi Di Puskesmas Bululwang Kabupaten Malang). Jurnal Hesti Wira Sakti, Edisi 1 Volume 4.

Syamsinar, I, 2015. Faktor-Faktor Yang Berhubungan Dengan Kelancaran Pengeluaran ASI Pada Ibu Post Partum Di Ruang Nifas Rumah Sakit TK.II Pelamonia. Jurnal: Ilmu Kedokteran Komonitas Fakultas Kedokteran Universitas Sam Ratulangi Edisi 2 Volume 5.

Sholichah, N, 2016. Hubungan Perawatan Payudara Pada Ibu Postpartum Dengan Kelancaran Pengeluaran Asi Di Desa Karang Duren Kecamatan Tengaran Kabupaten Semarang. Jurnal: Ilmu Keperawatan Unversitas Dipenegoro Edisi 3 Volume 2. 